\title{
Effectiveness of a focused, brief psychoed
program for parents of ADHD children: improvement of medication adherence and symptoms
}

\author{
This article was published in the following Dove Press journal: \\ Neuropsychiatric Disease and Treatment \\ 20 October 2015 \\ Number of times this article has been viewed
}

\section{Guan-nan Bai' \\ Yu-feng Wang ${ }^{2,3}$ \\ Li Yang ${ }^{2,3}$ \\ Wen-yi Niu'}

'Department of Social Medicine and Health Education, School of Public Health, Peking University, Beijing, People's Republic of China; ${ }^{2}$ Peking University Sixth Hospital/Institute of Mental Health, Key Laboratory of Mental Health, Ministry of Health, Beijing, People's Republic of China; ${ }^{3}$ National Clinical Research Center for Mental Disorders, Peking University Sixth Hospital, Beijing, People's Republic of China
Correspondence: Wen-yi Niu Department of Social Medicine and Health Education, School of Public Health, Peking University, 38 Xueyuan Road, Haidian District, Beijing 100191, People's Republic of China

Tel +861082801743

Email health1956@163.com

Li Yang

Peking University Sixth Hospital, 5I Huayuan Bei Road, Haidian District, Beijing I0019I, People's Republic of China

Tel +86 1062350880

Email yangli_pkuimh@bjmu.edu.cn
Objective: To evaluate the efficacy of a psychoeducation program for parents of children with ADHD in enhancing adherence to pharmacological treatment and improving clinical symptoms.

Methods: We developed a psychoeducation program based on the theory of planned behavior (TPB). Eighty-nine children with ADHD were cluster randomly assigned for their families to receive 3 months of well-structured psychoeducation (intervention group, $n=44$ ) or only general clinical counseling (control group, $n=45$ ). Parents in the intervention group were given an expert lecture (with slides and a parent manual), attended two expert-guided parent group sessions, and were invited to join a professional-guided online community. Measurement of parents' knowledge about ADHD, components of the TPB model, and child ADHD symptoms were taken before and after intervention. Medication adherence was assessed thoroughly at the end of the first and third months. Satisfaction with the psychoeducation program was assessed only in the intervention group. Two-independent-samples $t$-test, ANOVA, and chi-square test were employed to compare differences between groups.

Results: Compared to the control group, medication adherence in the intervention group was significantly higher after 1 and 3 months ( $97.7 \%$ intervention vs $75.6 \%$ control, $P=0.002$, and $86.4 \%$ intervention vs $53.3 \%$ control, $P=0.001$, respectively). Accordingly, the ADHD rating scale scores were lower in the intervention group than the control group after intervention (33.7 \pm 5.4 vs $45.1 \pm 7.9, P=0.008)$. Greater improvements in parents' knowledge about ADHD and many components of the TPB model were observed in the intervention group, especially increased intention to adhere to medication, compared to the control group $(P<0.001)$.

Conclusion: This psychoeducation program had a positive impact on both medication adherence and clinical symptoms of ADHD children. It could be considered as a potential beneficial supplement to clinical practice.

Keywords: attention deficit hyperactivity disorder, theory of planned behavior

\section{Introduction}

Attention deficit hyperactivity disorder (ADHD) is a common behavioral disorder in childhood and adolescence characterized by inattention, hyperactivity, and impulsivity inconsistent with age. The prevalence was similar worldwide. ${ }^{1}$ The worldwide pooled prevalence is $5.29 \%$. $^{2}$ Children and adolescents with ADHD may present many emotional and behavioral problems, as well as impaired social function. Some patients may suffer enduring impairments in adulthood. Owing to the chronic nature of ADHD, long-term pharmacotherapy is an important option for patients with 
moderate-to-severe symptoms and impairment. ${ }^{3}$ Despite the evidence-based effectiveness and safety of medication, adherence rates have been reported to be only $35 \%-80 \%{ }^{4}$ Nonadherence has been associated with poor response to medications ${ }^{5}$ and subsequent treatment failure, increasing the possibility of behavioral, academic, and social difficulties and impairment to family function over time. ${ }^{6,7}$ Parents play the most important role in making the decision to initiate medication. Recently, research has indicated that parents' perceptions of ADHD (eg, knowledge of ADHD, perceived severity, and cause of symptoms) and treatment acceptability are the main barriers to medication adherence, ${ }^{8}$ but these perceptions can be changed by intervention. Swanson suggested that psychoeducation offering disorderrelated information to parents might improve medication compliance. $^{9}$

Psychoeducation is defined as a specific therapeutic program focusing on didactic communication of information and providing patients and families with coping skills. ${ }^{10}$ It may be patient-, parent-, or school-focused. It is a cornerstone of treatments for ADHD. Up to now, there have only been nine studies that have investigated the effects of psychoeducation programs on clinical outcomes in children and adolescents with ADHD. Five of them were applied to parents, ${ }^{11-15}$ three to ADHD children/adolescents and their families, and one to teachers. ${ }^{16-19}$ Most psychoeducation has provided general information about ADHD, using lectures, group discussions, and manuals for parents. ${ }^{11,17,19}$ Studies have revealed that providing educational informatio increases knowledge, positive attitudes, and behaviors toward individuals with family members of ADHD. ${ }^{20}$ Recently, two psychoeducation programs with a randomized controlled trial (RCT) design indicated a statistically significant improvement in ADHD symptoms compared with a control group. One of these programs included 90-minute weekly sessions over 12 weeks that covered the disorder and treatment-related information as well as coping strategies, while the other adopted 5 weekly 90 -minute sessions (weeks 1-4 and week 9) including materials for session leaders, parents, and children. ${ }^{10,14}$ However, no significant differences in treatment adherence were found. Currently, there is an ongoing project in the Netherlands combining accelerated-track diagnosis, treatment planning, and psychoeducation at mental health centers. Clinical ADHD symptoms and adherence will be systematically assessed as the secondary outcome of this project. ${ }^{13}$

The above studies indicate that psychoeducation is a promising approach to improving ADHD adherence and, subsequently, clinical symptoms; however, several limitations need to be considered: 1) medication adherence is a complex behavior, but, according to our knowledge, no study included health behavior theories in their study design; 2) qualitative research approaches might be best suited to understanding the experience of parents from their perspectives, ${ }^{11}$ which might give better insight into how to develop effective interventions that they really need; and 3) culture-specific factors, such as psychosocial factors and stigmas, have an influence on adherence behavior; therefore, culture-adjusted intervention should be developed by combining multiple disciplines, including medical, social, psychological, and educational sciences.

Considering the above limitations, we used the theory of planned behavior (TPB) to establish a theoretical framework for psychoeducation program development and evaluation. Before developing interventions, we applied qualitative approaches, such as focus group interviews with clinicians and one-by-one interviews with parents, to ascertain their needs with regard to psychoeducation. Meanwhile, we gave consideration to the impact of culture on people's behaviors.

TPB is one of the most frequently cited and influential models for the prediction of human social behavior. ${ }^{21}$ The rationale behind this theory is that intention is the direct determinant of behavior, which is in turn influenced by perceptions of the likely outcomes of behavior and an evaluation of these outcomes as positive or negative (attitudes); perceptions of pressure from significant others to perform the behavior (subjective norms); and perceptions of confidence or self-efficacy in overcoming any barriers to the performance of the behavior (perceived behavioral control). ${ }^{22}$ In our study, we added extra factors related to adherence, including social demographic characteristics and self-efficacy, to the original model (Figure 1).

In our study, continuous provision of disorder/treatmentrelated knowledge and coping skills to parents via lectures, parent manuals, posters, group activities, and professional coaching in an online community was intended to strengthen positive attitudes to medication via decreasing misunderstandings of ADHD; meanwhile, including family members as well as the primary caregivers to lectures and group sessions acts on subjective norms, which might change negative attitudes in order to obtain family support by forming consistent understanding of the treatment. Additionally, group activities and online communities offer peer support for communicating experiences of managing ADHD children, which might reduce feelings of isolation, stress, and stigmatization, eventually enhancing behavioral control and self-efficacy. 


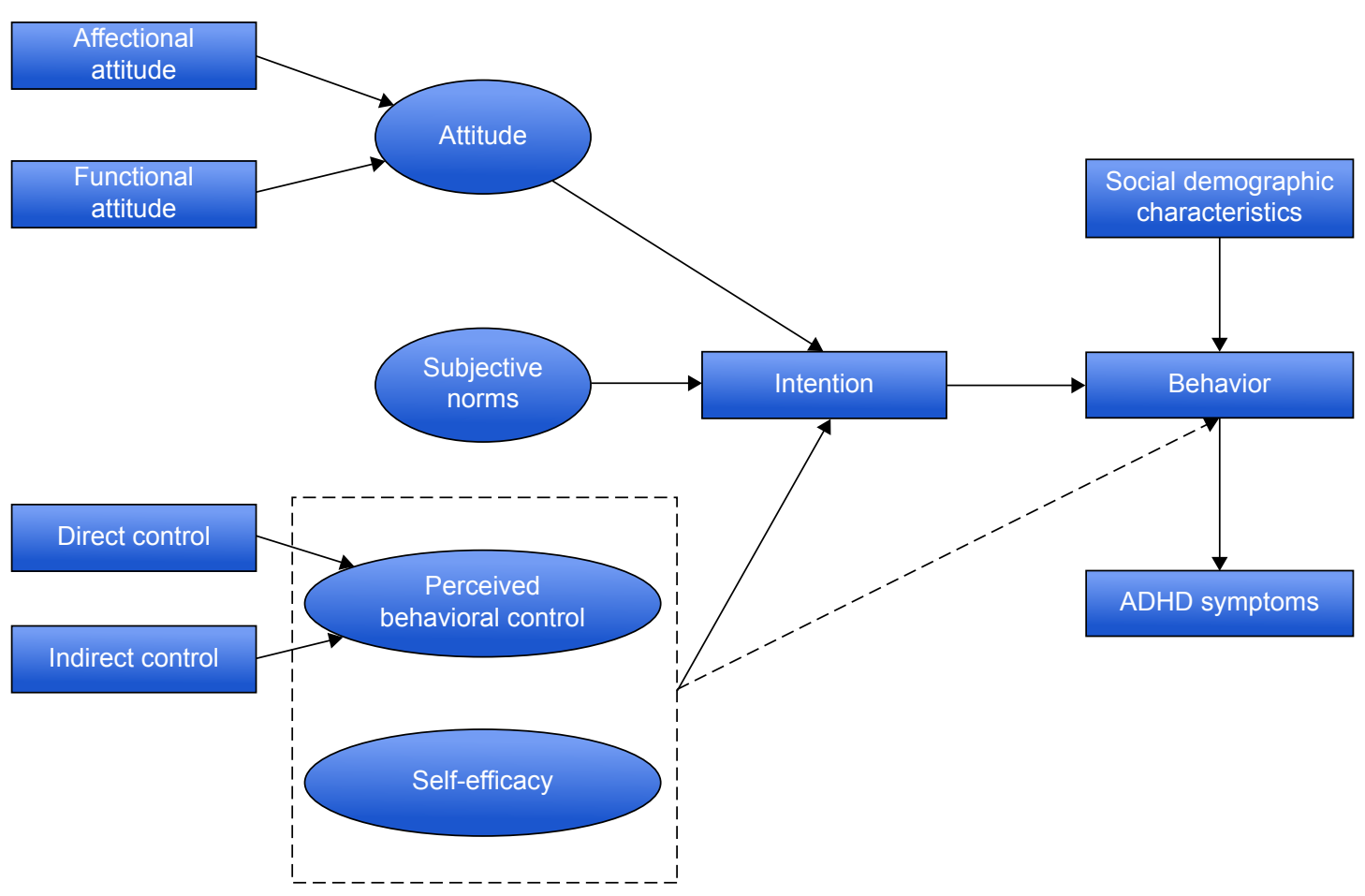

Figure I Theoretical framework for the study based on the theory of planned behavior.

This study aimed to develop a focused psychoeducation program for parents with ADHD children on the basis of health behavior theory and to evaluate its efficacy in raising parents' awareness and understanding of the disorder and its treatment, increasing adherence to pharmaceutical treatment, and improving clinical symptoms.

\section{Methods}

\section{Participants}

Eighty-nine families with children consecutively attending the Child and Adolescent Unit of Peking University Sixth Hospital (Beijing, People's Republic of China) were enrolled from August 2013 to December 2014. The inclusion criteria for the patients were: 1) children or adolescents aged 6-16 years; 2) diagnosed as having ADHD, with the diagnosis, based on the Diagnostic and Statistical Manual of Mental Disorders, Fourth Edition (DSM-IV), ${ }^{23}$ first made by a pediatric psychiatrist and then validated with a semi-structured interview with the parents and the child using Barkley's Clinical Diagnostic Interview Scale,${ }^{24}$ which had been used in our previous pharmacogenetic study; ${ }^{25} 3$ ) first referral to the hospital; and 4) a medication prescription, with the parents agreeing with the prescription. The exclusion criteria for the patients were: 1) unsuitability for medication treatment; 2) intellectual disability (IQ $<70$ ); 3) a pervasive developmental disorder or bipolar disorder or other psychoses making them unsuitable for participation in this study; 4) illiteracy of the parent/primary caregiver; and 5) unable to be followed up. Participants had to be the primary caregivers of the patients.

Patients and their families were recruited when they came to the hospital and got their assessment and were assigned to one cluster (intervention or control group). A cluster randomization scheme was used to allocate the clusters. The block size was 4 . The allocation scheme was performed by the primary investigator. The other investigator was informed of the allocation result after recruitment was done. This scheme assured a balance of subject numbers between the two groups, and possible contamination was avoided by arranging the groups' visits to the hospital for separate times. Both the intervention group and the control group began to take the medicine, osmotic controlled-release oral delivery system methylphenidate (OROS MPH) or atomoxetine, shortly after recruitment (Table S4). This study was approved by both the ethics committee of the Peking University Health Science Center (Beijing, People's Republic of China) and the institutional review board of Peking University Sixth Hospital. Recruitment, allocation, and analysis of this study are illustrated in Figure 2.

\section{Procedures}

The present study used a cluster randomized control design to assign parents to the intervention and control groups. Both groups 


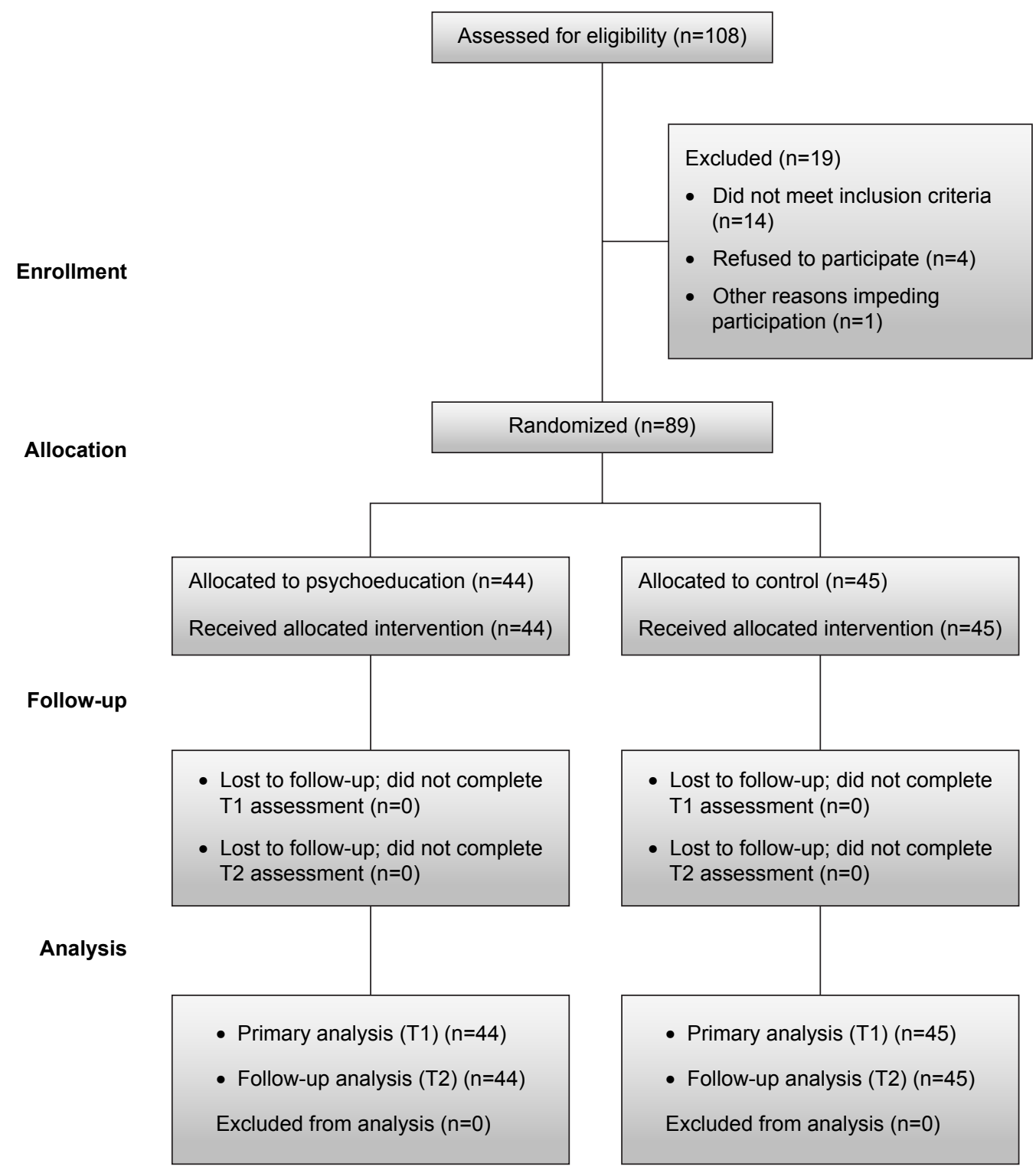

Figure 2 CONSORT diagram to illustrate study recruitment, random assignment, and data analysis. Notes: $\mathrm{TI}=$ end of the first month. $\mathrm{T} 2=$ end of the third month.

gave written informed consent for participation in the study, though they were blinded to what the other group received in terms of education.

Additional information about the implementation and contents of the psychoeducation program can be found in the Supplementary materials. A full description of developing and pretesting the psychoeducation program is available on request.

\section{Intervention group}

The intervention group was offered an expert-guided lecture (with slides) at the recruitment, and a parent manual was provided. Two sessions of parent group activities were conducted by health educators at the second and fourth weeks after initiating medication. Posters focused on medication adherence were also offered during the group activities. Throughout the 3-month intervention period, parents in the intervention group participated in an online community, where they could communicate with other parents, share experiences, and receive professional counsel. The above interventions focused on the main components of the TPB model, which also guided the focus group interview with clinicians and individual interviews with parents to evaluate parents' specific needs with regard to psychoeducation before the production of the health education materials and design of other activities. 


\section{Expert lecture and parent manual}

The lecture was given by an experienced clinical specialist using PowerPoint slides and presented core concerns summarized from our qualitative interviews. After the presentation, further discussion with the specialist regarding specific questions was available. The parent manual echoed the lecture and was used cooperatively. Both the lecture and the manual focused on five components: 1) showing physicians' understanding and willingness to help in order to build good patient-physician relationships; 2) disorder-related information, such as symptoms, potential causation/risk factors, and negative effects in the life course; 3 ) treatment-related information outlining pharmaceutical and non-pharmaceutical approaches, particularly regarding the effectiveness and adverse effects of medication; 4) barriers to adherence and coping skills; and 5) parenting skills. Additionally, skills for communicating with clinicians, teachers, and other family members were outlined in the parent manual.

More specifically, medication treatment-related information formed the core content of both the lecture and the parent manual. We presented graphs cited from two well-known longitudinal studies to convince parents of the effectiveness and safety of medications. One graph showed 2-year follow-up results of the MTA study, ${ }^{26}$ and the other graph displayed 5 years' follow-up of growth outcomes (height and weight) in children with and without medication, in which no significant differences were observed. ${ }^{27}$ Whether medication could impair growth and development of children was the main barrier to initiation of medication observed in our qualitative interviews conducted before developing interventions. Another major concern was about adverse effects. Information about common adverse effects, such as stomach discomfort, insomnia, fatigue, and practical coping skills, was described in detail, with advice such as "When children eat less, try to cook their favorite dishes, decrease the amount of food for each meal, and increase the frequency of meals per day". We also addressed interactive functions in the parent manual by including forms on which to record children's medication-taking behaviors; for example, the 7-day medication form instructed parents to record the name and dose of medication, time of taking pills, and whether or not the child had used the medication (and if not, to record the reasons); similarly, the adverse effects form required parents to describe observed adverse effects, their frequencies and durations, and whether the child could tolerate them. Parents were advised to show these forms when they visited clinicians, as they could provide clinicians more objective information and facilitate physician-patient communication. Additionally, small stories based on real cases in the qualitative interviews were also presented in the parent manual to give an idea of changes in children and their families after taking medication.

\section{Group sessions}

Two group sessions were conducted by a clinical assistant and supervised by a professor of health education at the second and fourth weeks after initiating medication. Each session took approximately 40 minutes. Adverse effects are often an important barrier to adherence in the beginning period of taking medication, so group sessions focused on tackling parents' concerns regarding this issue. A group of five to ten parents was asked to openly express their feelings, describing their problems or confusions. The clinical assistant wrote all the statements from the parents on the white board and guided group discussion among the parents, encouraging them to share their experiences, which helped parents to gain peer support in terms of both knowledge and emotion. Then, the assistant made a summary of the parents' questions regarding medication and invited a clinician to give professional answers of 10-15 minutes in length. In addition, the forms in the parent manual were requested to be presented during the session.

\section{Online community intervention}

The online community intervention was supplementary to the other approaches and was managed by the same clinical assistant. Minutes of the group sessions were posted, as were other health education materials offered for reading. In addition, information about clinical schedules and making appointments with physicians was also available in the online community, which helped parents who were not local residents. Real-time counseling with the clinical assistant and frequent communication with other parents was available in the online community.

\section{Control group}

The control group did not participate in the psychoeducation program, but only received general clinical counseling. After interventions were done, parents in the control group were offered the same psychoeducation interventions at their request. However, during the period of implementing the program, the control group was kept separate from the intervention group by the arrangement of different clinical visit times to effectively avoid contamination.

\section{Measures}

Measurements using questionnaires were taken at baseline (T0), the end of the first month (T1), and the end of the third 
month (endpoint) (T2). Well-trained interviewers guided parents through completing the questionnaires.

\section{Education log}

The involvement of each family in the educational activities, including use of the parent manual and participation in the didactic activities and group sessions, was recorded and analyzed.

\section{Knowledge about ADHD}

The self-designed knowledge questionnaire was applied at T0 and $\mathrm{T} 2$ and comprised 16 question items (five disorder-related and eleven medication-related) to measure parents' knowledge levels. Question items are demonstrated in Table S1 and the frequency of correct answers are shown in Table S2.

\section{TPB model}

Self-designed question items (Table S3) were developed to measure each component of the TPB model (demonstrated in Figure 1) at T0 and T2. Higher scores of variables in the TPB model indicate that a participant tends to enact greater adherence behavior.

\section{Medication adherence}

Eight questions were applied to measure medication adherence at $\mathrm{T} 1$ and $\mathrm{T} 3$. These questions included whether children continued their medication treatment; whether they took pills during the last weekend; how many days of not taking medication occurred in the last week; and how many days they did not take medication during the overall follow-up period. Reasons for stopping medication were also asked. The medication possession ratio (MPR), which is defined as the percent of days the patient complied with the prescription in a specific period, was calculated. Adherence was defined as MPR $\geq 0.70 .^{28}$

\section{Clinical assessment}

The ADHD Rating Scale-IV (ADHD-RS-IV) was used to assess the core symptoms of ADHD. ${ }^{29}$ It was completed by parents at $\mathrm{T} 1$ and $\mathrm{T} 3$. There are 18 items corresponding to the $D S M-I V$ criteria for ADHD. The first nine items constitute an inattention score, and the last nine items constitute a hyperactivity-impulsivity score. This scale has been translated into Chinese. The validity and reliability of the Chinese version, which was used in the present study, have been demonstrated by Su et al. ${ }^{30}$

\section{Satisfaction}

Subjective measures were assessed using a five-point scale from very dissatisfied/willing (1) to not satisfied/willing at all (5). The questions included parents' general satisfaction with the program, willingness to participate in the included activities, and whether they would be likely to recommend the program to other parents of children with ADHD.

\section{Statistical analysis}

Statistical analysis was performed using the Statistical Package for the Social Sciences (SPSSTM), version 19.0 (IBM Corporation, Armonk, NY, USA). The significance level was 0.05 . Descriptive statistics were used to characterize the study subjects. For continuous variables, group differences were assessed by using the two-independent-samples $t$-test, while for categorical variables, chi-square test and one-way ANOVA were employed. Correlations between intention and adherence behavior at the endpoint were checked using bivariate correlation analysis.

\section{Results \\ Baseline demographic characteristics}

Table 1 shows the demographic characteristics of the children and their parents. The mean age of patients in both groups was approximately 9 years. Most of the patients were boys $(>80 \%)$, and most of the parents who participated in this program were mothers $(>70 \%)$. The mean age of parents was approximately 40 years. Most of the parents had a college degree or above $(>60 \%)$, and more than $90 \%$ of the parents were employed.

\section{Scores of variables in the TPB model}

Table 2 gives an overview of the differences in the scores of variables in the TPB model between the intervention group and control group at the baseline and endpoint. At the baseline, significant differences were not observed for most variables,

Table I Demographic characteristics of patients and their parents $(\mathrm{N}=89)$

\begin{tabular}{llll}
\hline Characteristics & $\begin{array}{l}\text { Intervention } \\
\text { group }(\mathbf{n}=\mathbf{4 4})\end{array}$ & $\begin{array}{l}\text { Control } \\
\text { group (n=45) }\end{array}$ & P-value \\
\hline $\begin{array}{l}\text { Patient age, years (mean } \pm \text { SD) } \\
\text { Patient sex (\%) }\end{array}$ & $9.3 \pm 2.8$ & $9.6 \pm 2.9$ & 0.622 \\
$\quad$ Female & 13.6 & 15.6 & 0.798 \\
$\quad$ Male & 86.4 & 84.4 & \\
Parental age, years (mean \pm SD) & $40.7 \pm 7.1$ & $39.2 \pm 4.8$ & 0.916 \\
Parental sex (\%) & & & \\
$\quad \begin{array}{l}\text { Female } \\
\text { Male }\end{array}$ & 72.7 & 73.3 & 0.949 \\
Parental education level (\%) & 27.3 & 26.7 & \\
$\quad$ Below college & 34.1 & 40.0 & 0.564 \\
$\quad$ College and above & 65.9 & 60.0 & \\
Parental work status (\%) & & & 0.677 \\
$\quad$ Employed & 93.2 & 95.6 & \\
$\quad$ Unemployed & 6.8 & 4.4 & \\
\hline
\end{tabular}

Abbreviation: SD, standard deviation. 
Table 2 Comparison of variable scores in the theory of planned behavior model between the intervention group and control group at baseline and endpoint

\begin{tabular}{|c|c|c|}
\hline Items & $\begin{array}{l}\text { Intervention } \\
\text { group }(n=44)\end{array}$ & $\begin{array}{l}\text { Control } \\
\text { group }(n=45)\end{array}$ \\
\hline \multicolumn{3}{|l|}{ Baseline (mean $\pm \mathrm{SD}$ ) } \\
\hline Knowledge score & $8.7 \pm 3.1$ & $7.8 \pm 3.6$ \\
\hline Affectional attitude & $16.8 \pm 2.8$ & $16.3 \pm 2.8$ \\
\hline Functional attitude & $6.3 \pm 1.5$ & $6.3 \pm 2.4$ \\
\hline Subjective norms & $69.5 \pm 24.5$ & $64.5 \pm 24.7$ \\
\hline Direct control & $25.2 \pm 5.7$ & $24.6 \pm 7.2$ \\
\hline Indirect control & $19.2 \pm 2.9^{a}$ & $20.6 \pm 1.1$ \\
\hline Self-efficacy & $34.4 \pm 6.2^{\mathrm{a}}$ & $37.4 \pm 4.8$ \\
\hline Behavior intention & $6.1 \pm 1.5$ & $6.2 \pm 1.5$ \\
\hline \multicolumn{3}{|l|}{ Endpoint (mean $\pm S D$ ) } \\
\hline Knowledge score & $13.5 \pm 2.2^{\mathrm{b}, \mathrm{c}}$ & $5.4 \pm 3.8$ \\
\hline Affectional attitude & $12.7 \pm 2.0^{\mathrm{b}, \mathrm{c}}$ & $16.4 \pm 2.6$ \\
\hline Functional attitude & $6.2 \pm 1.4$ & $6.6 \pm 0.8$ \\
\hline Subjective norms & $89.6 \pm 18.6^{b, c}$ & $55.6 \pm 28.6$ \\
\hline Direct control & $31.2 \pm 3.4^{b, c}$ & $22.6 \pm 6.4$ \\
\hline Indirect control & $20.7 \pm 1.3^{\mathrm{b}, \mathrm{c}}$ & $18.0 \pm 3.9^{d}$ \\
\hline Self-efficacy & $39.9 \pm 3.8^{b, c}$ & $32.2 \pm 7.5^{d}$ \\
\hline Behavior intention & $6.6 \pm 1.3^{b}$ & $4.1 \pm 2.5^{d}$ \\
\hline
\end{tabular}

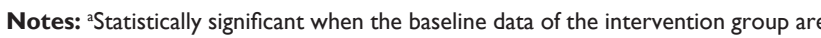
compared with the control group. ${ }^{b}$ Statistically significant when the endpoint data of the intervention group are compared with the control group. 'Statistically significant when the endpoint data are compared with baseline data within the intervention group. 'Statistically significant when the endpoint data are compared with baseline data within the control group.

Abbreviation: SD, standard deviation.

but, at the endpoint, compared with the control group, almost all variables in the TPB model measured in the intervention group showed significant differences. More specifically, after intervention, parents in the intervention group showed significantly higher condition/treatment-related knowledge compared to the control group ( 13.5 vs $5.4, P<0.05$ ); tended to have a more positive attitude to medication (affectional attitude: 12.7 vs 16.4 ); were more likely to get much more support from physicians and family members regarding children's medication treatment (subjective norms: 89.6 vs 55.6); and were more likely to manage the medication-taking behavior of the children (direct control: 31.2 vs 22.6; indirect control: 20.7 vs 18.0; self-efficacy: 39.9 vs 32.2). More importantly, parents in the intervention group tended to have stronger intentions to adhere to medication (behavior intention: 6.6 vs 4.1).

Within the intervention group, improvements of the same variables mentioned above, except behavior intention (6.6 vs 6.1), were also observed after the intervention.

\section{Treatment adherence}

The most prescribed ADHD agent at baseline and during the study for both groups was atomoxetine (approximately $70 \%$ ); the other was OROS MPH (Table S3). Medication use patterns were similar across the two groups $(P<0.05)$.
In the intervention group, at the end of the first month after starting treatment, compared with the control group, fewer children had stopped medication treatment (one in the intervention group, eleven in the control group), and intervention children demonstrated fewer days without taking pills (1.3 vs 6.6) and more compliance to medication (MPR: 0.98 vs 0.93 ). After the 3 months of pharmaceutical treatment, changes occurred in both groups. In the intervention group, compared with the control group, fewer patients had given up medication treatment (13.6\% vs $46.7 \%)$, and intervention patients demonstrated fewer days without taking pills (4.7 vs 30.6 ) and more likelihood to adhere to medication (MPR: 0.97 vs 0.63 ). The above differences were statistically significant $(P<0.05)$. The reasons for discontinuing medication treatment were similar between the two groups. The main reason was children's situations getting worse, and the second was forgetting to give pills to children. However, the percentages for both these reasons were higher in the control group. Figure 3 shows the changes in adherence measurements between $\mathrm{T} 1$ and $\mathrm{T} 2$, and Table 3 shows the results of all measured items regarding adherence.

\section{Clinical assessment}

Table 4 shows the comparison of ADHD-RS-IV scores in the intervention and control groups at $\mathrm{T} 0$ and $\mathrm{T} 2$. There were no significant differences in ADHD-RS-IV scores observed in the groups at baseline level. After psychoeducation of the parents, the scores of the intervention group dropped dramatically, while those of the control group stayed almost the same, except the hyperactivity score, which increased slightly. The differences in both the overall and subtype scores of the ADHD-RS-IV between the two groups were statistically significant at the end of the program.

\section{Parents' satisfaction}

Table 5 shows that $90.9 \%$ of parents were "very satisfied" with the overall psychoeducation program; $88.6 \%$ of parents were "very willing" to participate in similar activities in the future; and $90.9 \%$ were "very willing" to recommend the activities to other parents of ADHD children.

\section{Correlation analysis}

There were significant correlations between intention and adherence behavior for both groups at the endpoint (Table 6).

\section{Discussion}

ADHD is a disorder to which discrimination and stigma are attached. Given this, the psychosocial context should be 
$\multimap$ Intervention group -日-Control group

A

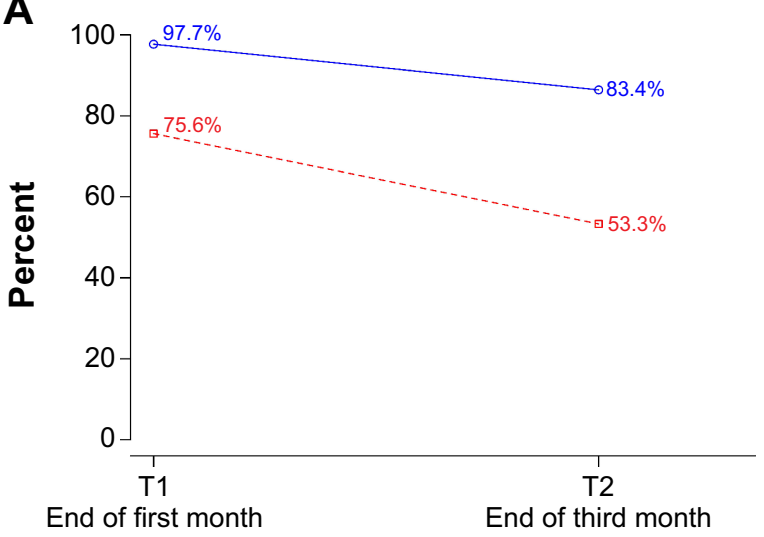

B

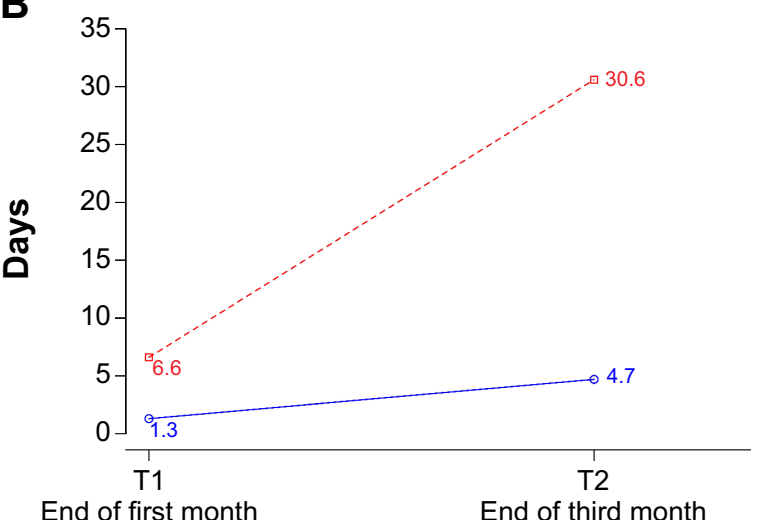

C

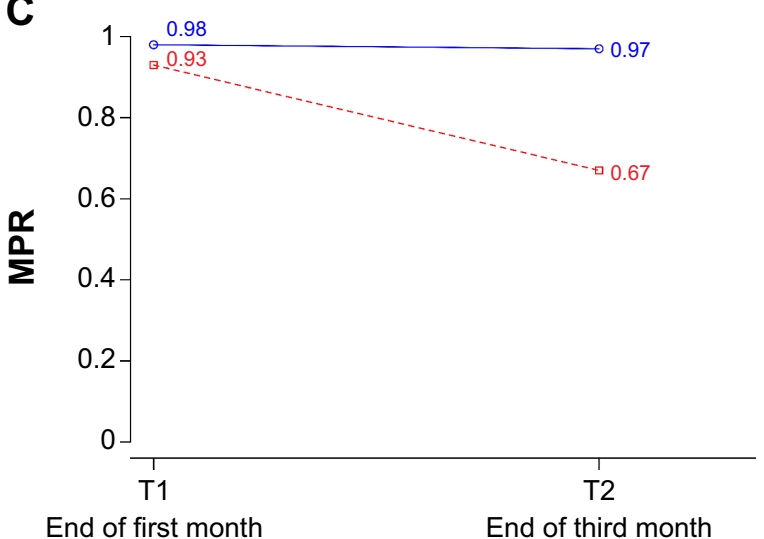

D

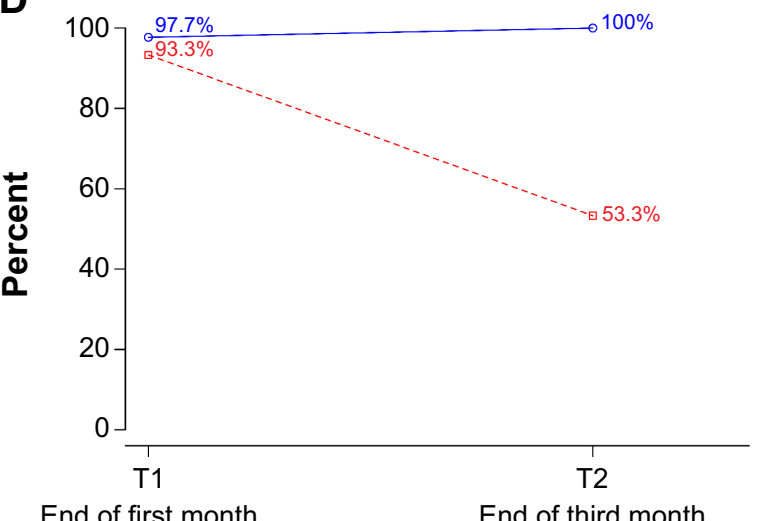

Figure 3 The measures of medication adherence.

Notes: (A) Percentage of patients who did not stop medication treatment. (B) Days without taking medication during the follow-up period. (C) Medication possession ratio (MPR). (D) Adherence rates at TI and T2.

taken into account to understand disorder-related problems, particularly poor medication adherence. Health behavior theories are helpful in understanding adherence behavior from a comprehensive perspective and in developing interventions accordingly. In our study, the TPB-based interventions were shown to be effective in increasing adherence behavior and improving ADHD symptoms.

The psychoeducation package included a parent manual, expert lecture, and parent group activities, as well as online intervention, providing parents with knowledge and social support, which was consistent with previous studies (eg, Krain et $\mathrm{al}^{31}$ and Corkum et $\mathrm{al}^{32}$ ) that showed that improving awareness of ADHD and treatment-related knowledge and attitudes was associated with improvement of adherence. In our study, the parent manual and expert lecture provided basic knowledge about ADHD symptoms, potential causation, negative effects, treatments, and child behavior-management skills. Subsequently, the parent group sessions and online counseling provided information related to questions generated during the treatment procedure, especially in the online community, where questions could be answered quickly to address knowledge barriers in medication treatment. Hack and $\mathrm{Chow}^{33}$ mentioned in their review that providing written instruction also helps with adherence, because written material allows patients to review information and decreases miscommunication. It has been reported that only approximately $50 \%$ of patients could recall the instructions from physicians during their last visit, ${ }^{34}$ so is a necessary supplement to clinical procedures.

After psychoeducation, the average knowledge score of the parents in the intervention group increased significantly compared to the baseline and was also significantly higher than the control group's endpoint knowledge score. The group sessions and online community in this study allowed parents to communicate with other parents and our clinical assistants to obtain both informational and emotional support, 
Table 3 Medication adherence of the intervention group and control group at the first and second follow-up

\begin{tabular}{|c|c|c|}
\hline Items & Intervention group & Control group \\
\hline \multicolumn{3}{|l|}{ First follow-up } \\
\hline Still taking medication (\%) (if yes) & $97.7^{\mathrm{a}}$ & 75.6 \\
\hline Medication possession ratio & $0.98^{\mathrm{a}}$ & 0.93 \\
\hline Adherence rate $(\%)$ & 97.7 & 93.3 \\
\hline Average number of days of discontinuation & $1.3^{\mathrm{a}}$ & 6.6 \\
\hline \multicolumn{3}{|l|}{ during the follow-up period } \\
\hline Took medication during the last weekend (\%) & $90.9^{a}$ & 68.9 \\
\hline Average number of days of discontinuation & $0.4^{\mathrm{a}}$ & 2.2 \\
\hline \multicolumn{3}{|l|}{ during the last week } \\
\hline \multicolumn{3}{|l|}{ Reasons for discontinuation (\%) } \\
\hline Forgot & 9.1 & 24.4 \\
\hline Situation getting better & $0^{\mathrm{a}}$ & 13.3 \\
\hline Situation getting worse & $11.4^{a}$ & 37.8 \\
\hline \multicolumn{3}{|l|}{ Second follow-up } \\
\hline Still taking medication (\%) (if yes) & $86.4^{b, c}$ & $53.3^{d}$ \\
\hline Medication possession ratio & $0.97^{b}$ & $0.67^{d}$ \\
\hline Adherence rate $(\%)$ & $100.0^{b}$ & $55.6^{d}$ \\
\hline Average number of days of discontinuation & $4.7^{\mathrm{b}}$ & $30.6^{d}$ \\
\hline \multicolumn{3}{|l|}{ during the follow-up period } \\
\hline Took medication during the last weekend (\%) & $86.4^{b}$ & 46.7 \\
\hline Average number of days of discontinuation & $1.0^{\mathrm{b}}$ & 3.3 \\
\hline \multicolumn{3}{|l|}{ during the last week } \\
\hline \multicolumn{3}{|l|}{ Reasons for discontinuation (\%) } \\
\hline Forgot & $15.9^{\mathrm{b}}$ & 37.8 \\
\hline Situation getting better & 4.5 & 8.9 \\
\hline Situation getting worse & $18.2^{\mathrm{b}}$ & 60.0 \\
\hline
\end{tabular}

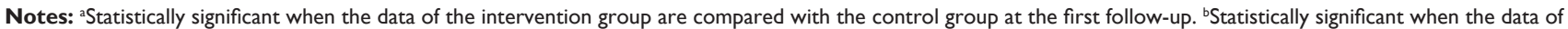
the intervention group are compared with the control group at the second follow-up. 'Statistically significant when the data of the second follow-up are compared with the first follow-up within the intervention group. ${ }^{\circledR}$ Statistically significant when the data of the second follow-up are compared with the first follow-up within the control group.

which resulted in improvements in parents' management skills of children's behavior as well as their own mental health statuses. A randomized controlled study of Internetbased parent management training demonstrated that, after Internet intervention, parents reported fewer behavior

Table 4 Comparison of ADHD symptom scores between the intervention group and control group at baseline and endpoint

\begin{tabular}{lll}
\hline ADHD-RS-IV items & $\begin{array}{l}\text { Intervention } \\
\text { group }(\mathbf{n}=\mathbf{4 4})\end{array}$ & $\begin{array}{l}\text { Control } \\
\text { group }(\mathbf{n = 4 5})\end{array}$ \\
\hline Baseline (mean \pm SD) & & \\
ADHD total score & $49.9 \pm 11.5$ & $48.1 \pm 8.1$ \\
Inattention score & $26.1 \pm 5.9$ & $25.9 \pm 3.7$ \\
Hyperactivity score & $13.2 \pm 4.1$ & $12.4 \pm 3.6$ \\
Impulsivity score & $10.6 \pm 3.4$ & $9.8 \pm 2.8$ \\
Endpoint (mean \pm SD) & & \\
ADHD total score & $33.7 \pm 5.4^{\mathrm{a}, \mathrm{b}}$ & $45.1 \pm 7.9$ \\
Inattention score & $18.8 \pm 3.0^{\mathrm{a}, \mathrm{b}}$ & $25.4 \pm 4.4$ \\
Hyperactivity score & $7.7 \pm 2.0^{\mathrm{a}, \mathrm{b}}$ & $10.6 \pm 2.9^{\mathrm{c}}$ \\
Impulsivity score & $7.1 \pm 1.9^{\mathrm{a}, \mathrm{b}}$ & $9.1 \pm 2.6$ \\
\hline
\end{tabular}

Notes: aStatistically significant when the endpoint data of the intervention group are

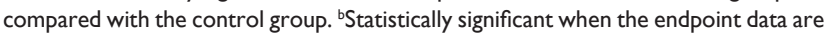
compared with baseline data within the intervention group. 'Statistically significant when the endpoint data are compared with baseline data within the control group. Abbreviations: ADHD-RSV-IV, ADHD Rating Scale-IV; SD, standard deviation; $A D H D$, attention deficit hyperactivity disorder. problems, and the positive effect on children's behavior was maintained at 6-month follow-up. ${ }^{35}$ We also measured such changes by using variables in the TPB model, for example, affectional attitude to the medication; subjective norms, showing social support that parents got from their surroundings; self-efficacy, indicating their confidence to handle the management of ADHD children; and behavior intention, showing parents' willingness toward compliance to pills. After intervention, scores of the abovementioned variables were significantly higher in the intervention group compared with the control group. Meanwhile, the measurements of adherence showed that adherence was better in the intervention group compared to the control group at the end of the first and third months in our study.

Our study addressed educational components and emotional components, because the needs evaluation showed that, for parents of new patients (new patients meaning those who had never taken medication before), the main barriers to initiating medication and continuing treatment were identified as a lack of correct disorder/treatment-related knowledge, less emotional support from their surroundings, and feeling isolated. This comprehensive education program addressed these issues by 
Table 5 Satisfaction of parents with the psychoeducation program in the intervention group $(n=44)$

\begin{tabular}{|c|c|c|c|c|c|}
\hline \multirow[t]{2}{*}{ Items } & \multicolumn{5}{|c|}{ Rating } \\
\hline & $\mathbf{I}$ & 2 & 3 & 4 & 5 \\
\hline Overall satisfaction (\%) & 90.9 & 9.1 & 0.0 & 0.0 & 0.0 \\
\hline $\begin{array}{l}\text { Willingness to attend the same or similar psychoeducation } \\
\text { activities in the future (\%) }\end{array}$ & 88.6 & 11.4 & 0.0 & 0.0 & 0.0 \\
\hline $\begin{array}{l}\text { Willingness to recommend the psychoeducation } \\
\text { program to other parents of children with ADHD (\%) }\end{array}$ & 90.9 & 9.1 & 0.0 & 0.0 & 0.0 \\
\hline
\end{tabular}

Note: $\mathrm{I}-5=$ very satisfied/willing to not satisfied/willing at all.

Abbreviation: ADHD, attention deficit hyperactivity disorder.

providing knowledge and emotional support/comfort to parents, as well as providing skills to manage medication compliance. Significant benefits of behavioral modification therapy over usual community comparison were not found, and that medication management extended 10 months beyond the intensive treatment phase. ${ }^{36}$ Although it was indicated in the MTA study, significant benefits of behavioral modification therapy over community comparison were not found, it did not target the adherence. In our study, behavioral interventions were embedded in the whole program, but were not the main component. Instead, efforts were made primarily to increase awareness of ADHD and treatment, which was expected to change attitudes to medication; additionally, medication management skills were developed, for example, through the use of 7-day medication and adverse effects forms as reminders to parents to adhere to medication. The whole set of interventions considered the psychosocial context by offering parents emotional support, as mentioned above, which aimed to improve behavioral control and self-efficacy to manage medication adherence behavior. Finally, as a whole, this psychoeducation program was expected to improve parents' intentions, which was expected to be the primary factor for eliciting behavior change.

Montoya et al performed an RCT to evaluate the effect of a parental psychoeducation program on medication persistence in ADHD children and found no significant difference between the psychoeducation and control groups in terms of the proportion of patients who discontinued pharmacologic treatment. ${ }^{10}$ This study was among the earliest RCTs on ADHD psychoeducation; however, the authors did not find an effect on the persistence of medication nor a relationship between medication adherence and symptom improvement. A possible weakness of the study design was the amount of time that lapsed between education and evaluation: the education lasted until week 9, whereas the evaluation took place over 12 months. The effects of short-term education might not last for a long time. This point was suggested in our previous study (unpublished data, 2010), in which we educated parents for 1 month. The adherence rates after 1 month, 6 months, and 12 months were $77.5 \%, 36.6 \%$, and $28.6 \%$ and $63.8 \%, 35.6 \%$, and $21.2 \%$ for the education group and control group, respectively. Significant differences in medication adherence were only detected in the first month, which suggested reinforcement of the education program was warranted for improved longterm persistence with pharmacological treatment.

\section{Strengths and limitations}

The most important strength of the current study is that it demonstrates well the relationship between a focused, brief psychoeducation program for parents of ADHD children and improvement in medication adherence, as well as the possible underlying mechanism through which knowledge increases and behavioral intent toward the pharmacological treatment is enhanced. Although two RCTs had previously investigated the effects of psychoeducation on ADHD and reported symptom improvement, neither of them gave a satisfactory interpretation of the mechanism. ${ }^{10,14}$

Table 6 Correlations between intention and adherence behavior in the intervention and control groups at the third month after initiating medication

\begin{tabular}{|c|c|c|c|c|}
\hline \multirow[t]{2}{*}{ Items } & \multicolumn{2}{|c|}{ Intervention group $(n=44)$} & \multicolumn{2}{|l|}{ Control group $(n=45)$} \\
\hline & Pearson coefficient & $P$-value & Pearson coefficient & $P$-value \\
\hline MPR & 0.76 & $<0.001$ & 0.75 & $<0.001$ \\
\hline Adherence rate ${ }^{a}$ & 0.42 & 0.004 & 0.72 & $<0.001$ \\
\hline Medication discontinuation & 0.65 & $<0.001$ & 0.76 & $<0.001$ \\
\hline
\end{tabular}

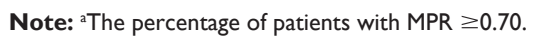

Abbreviation: MPR, medication possession ratio. 
Other advantages of this study include that we conducted a thorough investigation by using a qualitative interview method to systematically explore parents' opinions toward ADHD and medication treatment. The development of the subsequent psychoeducation program was rooted in and concentrated on the findings from the needs evaluation. Secondly, we started the intervention as early as possible before parents made the decision to initiate treatment by providing necessary information to parents via an expert lecture and parent manual when their children came to the hospital for the first-time assessment. Corkum et $\mathrm{al}^{32}$ also found in their study that, before patients made a decision regarding treatment, provision with relevant information regarding the treatment could increase treatment adherence - a finding that is consistent with our study. Thirdly, in our study, adherence was measured in a more detailed way by using eight questions about current medication adherence and medication adherence during the last weekend of follow-up, the number of days pills were discontinued during the follow-up period, and the reason for discontinuation, which gave a deeper insight into medication adherence behavior. Lastly, multiple disciplines (eg, communication sciences, linguistics, social sciences, social psychology, epidemiology, and health education) were considered together in our study, particularly in the study design, needs evaluation, and development of the intervention package.

There are, however, some limitations in this study. Rigsby et $\mathrm{al}^{37}$ found that frequent contact with patients could increase medication adherence. In our study, we followed up 1 month and 3 months after medication initiation; moreover, the clinical assistants who managed the online community maintained interaction with parents almost on a daily basis. Therefore, it was not possible to avoid bias. Secondly, even though we measured adherence thoroughly, the titration dose of medications was not measured. Normally, pediatricians prescribe a medication at the lowest dose and increase to the target dose over time. However, during the follow-up, we found that some parents did not follow this dose schedule, with some of them staying at the low dose because of adverse effects. In future ADHD medication adherence research, whether patients follow the prescribed titration dose should be included in the measurement of adherence. Further, the MPR was calculated by using days of discontinuation divided by the days of the whole follow-up period. Adherence was defined when MPR $\geq 0.70 .{ }^{38}$ In this way, the adherence rate of the intervention group after the 3-month intervention was $100 \%$, but actually there were patients who had already stopped the medication treatment. This definition of adherence neglected the influence of discontinuation.

\section{Conclusion}

Despite some limitations, this psychoeducation program provides a new approach to improving medication adherence and clinical symptoms of ADHD children in the clinical setting. Long-term efficacy of the intervention should be studied in future research.

\section{Acknowledgments}

We thank all the parents who participated in this program. We thank all who volunteered in the pretesting of the educational materials. We also appreciate the help of Eli Lilly for their coordination in the program. This research was funded by the Capital Health Development Research Fund (2011-4024-04), the Major State Basic Research Development Program of China (973 Program, 2014CB846100), the National Natural Science Foundation of China (81471381), and the National Key Technology Research and Development Program of the Ministry of Science and Technology of China (grant number 2015BAI13B01).

\section{Disclosure}

The authors report no conflicts of interest in this work.

\section{References}

1. Faraone SV, Sergeant J, Gillberg C, Biederman J. The worldwide prevalence of ADHD: is it an American condition? World Psychiatry. 2003;2(2):104-113.

2. Polanczyk G, de Lima MS, Horta BL, Biederman J, Rohde LA. The worldwide prevalence of ADHD: a systematic review and metaregression analysis. Am J Psychiatry. 2007;164(6):942-948.

3. Attention Deficit Hyperactivity Disorder: Diagnosis and Management of ADHD in Children, Young People and Adults. NICE clinical guideline 72. Manchester: National Institute for Health and Clinical Excellence; 2008. Available from: www.nice.org.uk/CG072. Accessed.

4. McGough JJ, Smalley SL, McCracken JT, et al. Psychiatric comorbidity in adult attention deficit hyperactivity disorder: findings from multiplex families. Am J Psychiatry. 2005;162(9):1621-1627.

5. Hong J, Novick D, Treuer T, et al. Predictors and consequences of adherence to the treatment of pediatric patients with attention-deficit/ hyperactivity disorder in Central Europe and East Asia. Patient Prefer Adherence. 2013;7:987-995.

6. Adler LD, Nierenberg AA. Review of medication adherence in children and adults with ADHD. Postgrad Med. 2010;122(1):184-191.

7. Schachar R. Attention deficit hyperactivity disorder in children, adolescents, and adults. Continuum (Minneap Minn). 2009;15:78-97.

8. Corkum P, Bessey M, McGonnell M, Dorbeck A. Barriers to evidencebased treatment for children with attention-deficit/hyperactivity disorder. Atten Defic Hyperact Disord. 2015;7(1):49-74.

9. Swanson J. Compliance with stimulants for attention-deficit/ hyperactivity disorder: issues and approaches for improvement. CNS Drugs. 2003;17(2):117-131.

10. Montoya A, Hervas A, Fuentes J, et al. Cluster-randomized, controlled 12-month trial to evaluate the effect of a parental psychoeducation program on medication persistence in children with attentiondeficit/hyperactivity disorder. Neuropsychiatr Dis Treat. 2014;10: 1081-1092.

11. McCleary L, Ridley T. Parenting adolescents with ADHD: evaluation of a psychoeducation group. Patient Educ Couns. 1999;38(1):3-10. 
12. Monastra VJ. Overcoming the barriers to effective treatment for attention-deficit/hyperactivity disorder: a neuro-educational approach. Int J Psychophysiol. 2005;58(1):71-80.

13. Janssen M, Wensing M, van der Gaag RJ, Cornelissen I, van Deurzen P, Buitelaar J. Improving patient care for attention deficit hyperactivity disorder in children by organizational redesign (Tornado program) and enhanced collaboration between psychiatry and general practice: a controlled before and after study. Implement Sci. 2014;9:155.

14. Ferrin M, Moreno-Granados JM, Salcedo-Marin MD, Ruiz-Veguilla M, Perez-Ayala V, Taylor E. Evaluation of a psychoeducation programme for parents of children and adolescents with ADHD: immediate and long-term effects using a blind randomized controlled trial. Eur Child Adolesc Psychiatry. 2014;23(8):637-647.

15. Sonuga-Barke EJ, Daley D, Thompson M, Laver-Bradbury C, Weeks A. Parent-based therapies for preschool attention-deficit/hyperactivity disorder: a randomized, controlled trial with a community sample. J Am Acad Child Adolesc Psychiatry. 2001;40(4):402-408.

16. Ialongo NS, Horn WF, Pascoe JM, et al. The effects of a multimodal intervention with attention-deficit hyperactivity disorder children: a 9-month follow-up. J Am Acad Child Adolesc Psychiatry. 1993;32(1):182-189.

17. Lopez MA, Toprac MG, Crismon ML, Boemer C, Baumgartner J. A psychoeducational program for children with ADHD or depression and their families: results from the CMAP feasibility study. Community Ment Health J. 2005;41(1):51-66.

18. Svanborg P, Thernlund G, Gustafsson PA, Hägglöf B, Poole L, Kadesjö B. Efficacy and safety of atomoxetine as add-on to psychoeducation in the treatment of attention deficit/hyperactivity disorder: a randomized, doubleblind, placebo-controlled study in stimulant-naïve Swedish children and adolescents. Eur Child Adolesc Psychiatry. 2009;18(4):240-249.

19. Miranda A, Presentación MJ, Soriano M. Effectiveness of a schoolbased multicomponent program for the treatment of children with ADHD. J Learn Disabil. 2002;35(6):546-562.

20. Nussey C, Pistrang N, Murphy T. How does psychoeducation help? A review of the effects of providing information about Tourette syndrome and attention-deficit/hyperactivity disorder. Child Care Health Dev. 2013;39(5):617-627.

21. Ajzen I. The theory of planned behaviour: reactions and reflections. Psychol Health. 2011;26(9):1113-1127.

22. Mullan B, Allom V, Sainsbury K, Monds LA. Examining the predictive utility of an extended theory of planned behaviour model in the context of specific individual safe food-handling. Appetite. 2015;90:91-98.

23. Barkley RA. Attention-Deficit Hyperactivity Disorder: A Handbookfor Diagnosis and Treatment. 2nd ed. New York: Guilford Press; 1998.

24. Diagnostic and Statistical Manual Of Mental Disorders, Fourth Edition. Washington: American Psychiatric Association; 1994.
25. Yang L, Wang Y, Li J, Faraone SV. Association of norepinephrine transporter gene with methylphenidate response. J Am Acad Child Adolesc Psychiatr. 2004;43(9):1154-1158.

26. Swanson JM, Hinshaw SP, Arnold LE, et al. Secondary evaluations of MTA 36-month outcomes: propensity score and growth mixture model analyses. J Am Acad Child Adolesc Psychiatry. 2007;46(8): 1003-1014.

27. Donnelly C, Bangs M, Trzepacz P, et al. Safety and tolerability of atomoxetine over 3 to 4 years in children and adolescents with ADHD. J Am Acad Child Adolesc Psychiatry. 2009;48(2):176-185.

28. Case BG. Nonadherence: the silent majority. J Am Acad Child Adolesc Psychiatry. 2011;50(5):435-437.

29. DuPaul GJ, Power TJ, Anastopoulos AD, Reid R. ADHD Rating Scale-IV: Checklists, Norms, and Clinical Interpretation. New York: Guilford Press; 1998.

30. Su LY, Geng YG, Wang H, Du YS. Norm of ADHD rating scale parent version in Chinese urban children. Zhongguo Shiyong Erke Zazhi. 2006;21:833-836. Chinese.

31. Krain AL, Kendall PC, Power TJ. The role of treatment acceptability in the initiation of treatment for ADHD. J Atten Disord. 2005; $9(2): 425-434$.

32. Corkum P, Rimer P, Schachar R. Parental knowledge of attention-deficit hyperactivity disorder and opinions of treatment options: impact on enrollment and adherence to a 12-month treatment trial. Can J Psychiatry. 1999;44(10):1043-1048.

33. Hack S, Chow B. Pediatric psychotropic medication compliance: a literature review and research-based suggestions for improving treatment compliance. J Child Adolesc Psychopharmacol. 2001;11(1):59-67.

34. Osterberg L, Blaschke T. Adherence to medication. $N$ Engl J Med. 2005;353(5):487-497.

35. Enebrink P, Högström J, Forster M, Ghaderi A. Internet-based parent management training: a randomized controlled study. Behav Res Ther. 2012;50(4):240-249.

36. MTA Cooperative Group. National Institute of Mental Health Multimodal Treatment Study of ADHD follow-up: 24-month outcomes of treatment strategies for attention-deficit/hyperactivity disorder. Pediatrics. 2004;113(4):754-761.

37. Rigsby MO, Rosen MI, Beauvais JE, et al. Cue-dose training with monetary reinforcement: pilot study of an antiretroviral adherence intervention. J Gen Intern Med. 2000;15(12):841-847.

38. Avins AL, Pressman A, Ackerson L, Rudd P, Neuhaus J, Vittinghoff E. Placebo adherence and its association with morbidity and mortality in the studies of left ventricular dysfunction. J Gen Intern Med. 2010;25(12):1275-1281. 


\section{Supplementary materials \\ Methods \\ Development of the psychoeducation program}

The educational materials included detailed parent manuals, posters, and presentation slides. The design of the educational materials was guided by evaluation of the parents' needs for disorder-related information and skills and then discussed and revised by experts in ADHD. The contents included knowledge, skills, record-keeping, and expert-guided interaction activities and were expressed in Chinese culture-adjusted style. Pictures were added to make the materials lively and the concepts easy to understand. The key concepts were echoed in multiple materials in order to strengthen retention. We first ran a pretest of the educational materials via individual interviews with the parents. We asked about the comprehensibility, acceptability, and persuasiveness of each page, paragraph, picture, and slide, then made further revisions accordingly.

\section{Expert lecture and parent manual}

The expert presentation and the parent manual echoed each other and were used cooperatively. In the presentation, the specialist communicated the necessary information with the parents in simple words; the information also could be found in the manual. The parents' feedback was obtained through activities outlined in the parent manual, to make sure they understood the information properly.

The contents of the educational materials included:

1. Understanding and cooperation. The specialist expressed understanding of the effort the parents made to take care of their ADHD children. The attitude of acceptance and support was helpful for the establishment of a cooperative relationship.

2. Disorder-related information. The manifestation and diagnostic process of ADHD were introduced in the expert presentation. Simple questions were included in the manual to obtain feedback from the parents, so that whether the parents had understood the symptoms and the diagnosis could be checked and further discussed. We emphasized the definition of "disorder", and corrected the misunderstanding of "disease". Agreement with the diagnosis was obtained not only from the parents, but also from the eldest member of the family (in Chinese culture, the elder member of a family often makes decisions). We suggested to the parents that the children's behavior had a negative impact on children's lives that necessitated intervention. We also communicated the outcomes of ADHD with the parents and told them that treatment discontinuation might cause lifelong problems.

3. Treatment-related information. Pharmacological and nonpharmacological treatments were introduced to the parents. The results of the multimodal treatment study (MTA) ${ }^{1}$ were used to interpret the comparison of the treatments. Then the parents had an opportunity to choose the treatment they desired. The expert discussed the best treatment for the child with each parent individually when necessary. As many children would need medication, the pharmacological mechanisms, therapeutic effects, and side effects were introduced. Parents' attitudes toward pharmacological therapy were noted. Their concerns about addiction, long-term effects, and influence on intelligence and growth, as well as management of side effects were addressed one by one. Once a parent decided to let their child take the medicine, they were guided in how to administrate the medicine properly and take records of side effects in preparation for visiting a doctor.

4. Adherence to the medication. The importance of persistence in medication and when to stop medication were discussed with the parents.

5. Parenting skills for ADHD children and adolescents. General parenting skills and behavior-management strategies were introduced to the parents; these included changing the environment and lifestyle, skills for managing ADHD symptoms, and positive discipline.

After the presentation, any questions from the parents could be further addressed by the expert.

\section{Group session at the second week}

The group session was led by a clinical assistant. In this session, parents discussed the side effects of medication. They first played a game, "draw your face", by which parents' attitudes toward the medication could be quickly ascertained. Then the parents shared their records of medicine-taking and side effects. At the end of the session, a psychiatrist addressed the parents' concerns about side effects and discussed how to deal with the side effects. Advice on improving diet and sleep were summarized and provided.

\section{Group session at the fourth week}

In the fourth week, adherence to medication was discussed. "Draw your face" was again the opening game. Then, the parents shared their feelings about their children's improvement. After that, they were guided in a game to evaluate their expectations. The records of medicine-taking were shared. Then the group proceeded into a group discussion in 
terms of: Why does medication need to be continued? What is good compliance? What were the factors that influenced the medication adherence? How should these factors be dealt with? and What was the parent's plan for managing the medication? At the end, the psychiatrist summarized the answers, with emphasis on maintenance of the medication.

Table SI Question items in the knowledge questionnaire

Question I: Core symptoms of ADHD.

Question 2: Potential causes of ADHD.

Question 3: Negative effects of ADHD.

Question 4: ADHD is a chronic disorder. Yes/No/l do not know

Question 5: Treatments for ADHD include both medication and non-medication methods. Yes/No/l do not know

Question 6: Medication treatment is regarded as the first choice for preschool children with ADHD. Yes/No/l do not know

Question 7: Medication could improve children's ADHD symptoms. Yes/No/l do not know

Question 8: The efficacy of non-medication treatment methods is uncertain and slow, with limited evidence. Yes/No/l do not know

Question 9: For most ADHD children, behavioral-only treatment could not work better than medication treatment. Yes/No/l do not know

Question 10: Medication treatment would not result in drug addiction. Yes/No/l do not know

Question II: Adverse effects of drugs are slight, short-term, and manageable. Yes/No/l do not know

Question 12: Medication treatment would not impact children's intelligence and growth. Yes/No/l do not know

Question 13: Adherence is necessary. Yes/No/l do not know

Question 14: Nonadherence would cause the recurrence of ADHD symptoms or even worse outcomes. Yes/No/l do not know

Question I5: How to make a correct decision to stop drug use.

Question 16: What are the adverse effects of ADHD?

Abbreviation: ADHD, attention deficit hyperactivity disorder.

Table S2 The frequency of correct answers to each question in the knowledge questionnaire

\begin{tabular}{|c|c|c|c|c|}
\hline \multirow[t]{2}{*}{ Items } & \multicolumn{2}{|l|}{ Baseline (\%) } & \multicolumn{2}{|l|}{ Endpoint (\%) } \\
\hline & Intervention group & Control group & Intervention group & Control group \\
\hline Question I & 72.7 & $60.0^{\mathrm{a}, \mathrm{b}}$ & 97.7 & 75.6 \\
\hline Question 2 & 50.0 & $53.3^{\mathrm{a}, \mathrm{b}}$ & 84.1 & $24.4^{c}$ \\
\hline Question 3 & 77.3 & $73.3^{\mathrm{a}, \mathrm{b}}$ & 95.5 & 66.7 \\
\hline Question 4 & 59.1 & $44.4^{\mathrm{a}, \mathrm{b}}$ & 84.1 & $20.0^{c}$ \\
\hline Question 5 & 79.5 & $73.3^{\mathrm{a}}$ & 90.9 & $44.4^{c}$ \\
\hline Question 6 & 43.2 & $3|.|^{a, b}$ & 75.0 & $8.9^{c}$ \\
\hline Question 7 & 79.5 & $68.9^{\mathrm{a}, \mathrm{b}}$ & 100.0 & 60.0 \\
\hline Question 8 & 38.6 & $37.8^{\mathrm{a}, \mathrm{b}}$ & 63.6 & $11.1^{c}$ \\
\hline Question 9 & 75.0 & $60.0^{\mathrm{a}, \mathrm{b}}$ & 97.7 & $80.0^{c}$ \\
\hline Question 10 & 25.0 & $22.2^{\mathrm{a}, \mathrm{b}}$ & 77.3 & 15.6 \\
\hline Question II & 34.5 & $3|.|^{a, b}$ & 75.0 & $13.3^{c}$ \\
\hline Question 12 & 25.0 & $20.0^{\mathrm{a}, \mathrm{b}}$ & 79.5 & 8.9 \\
\hline Question 13 & 52.3 & $46.7^{\mathrm{a}, \mathrm{b}}$ & 88.6 & $22.2^{c}$ \\
\hline Question 14 & 56.8 & $57.8^{\mathrm{a}, \mathrm{b}}$ & 90.9 & $31.1^{\mathrm{c}}$ \\
\hline Question 15 & 81.8 & $86.7^{\mathrm{a}}$ & 93.2 & $53.3^{c}$ \\
\hline Question 16 & 22.7 & $13.3^{\mathrm{a}, \mathrm{b}}$ & 50.0 & 13.3 \\
\hline
\end{tabular}

Notes: aStatistically significant when the endpoint data of the intervention group are compared with the control group. bStatistically significant when the endpoint data are compared with baseline data within the intervention group. 'Statistically significant when the endpoint data are compared with baseline data within the control group. 
Table S3 Question items in the theory of planned behavior model used in the study

\begin{tabular}{|c|c|c|}
\hline Variables & Subvariables & Question items \\
\hline \multirow[t]{11}{*}{ Attitude } & Affectional attitude ${ }^{\mathrm{a}}$ & I don't think ADHD is a disorder. \\
\hline & & Medication treatment is needed for children with ADHD when necessary. \\
\hline & & If children are adherent to medication treatment, their symptoms of ADHD will improve. \\
\hline & & I am scared of adverse effects of medications and I am afraid that taking medication would \\
\hline & & damage the growth and development of my child. \\
\hline & & I am afraid that my child would face stigma and social discrimination once others know he/she \\
\hline & & is taking ADHD medication. \\
\hline & Functional attitude ${ }^{b}$ & Attention problems, hyperactivity, impulsiveness \\
\hline & & Emotional problems \\
\hline & & Academic performance \\
\hline & & Social relationships \\
\hline \multirow[t]{4}{*}{ Subjective norms } & & To what extent has the physician suggested medication treatment? ${ }^{c}$ \\
\hline & & To what extent do you follow the physician's suggestions to take medication? ${ }^{d}$ \\
\hline & & What do your family, relatives, and friends think about medication treatment? ${ }^{c}$ \\
\hline & & To what extent do you agree with their opinions? ${ }^{d}$ \\
\hline \multirow{9}{*}{$\begin{array}{l}\text { Perceived behavioral } \\
\text { control }\end{array}$} & Direct controle & I am able to manage medication use to make sure my child takes medication daily. \\
\hline & & I am able to visit the physician as scheduled and describe what happened to my child while \\
\hline & & taking medication. \\
\hline & & I am able learn to how my child performs at school while taking medication. \\
\hline & Indirect control ${ }^{f}$ & Adverse effects of medication \\
\hline & & Long-term treatment period \\
\hline & & High cost of medication \\
\hline & & Lack of ADHD-related knowledge \\
\hline & & Afraid of stigma attached to ADHD and medication. \\
\hline Intention ${ }^{g}$ & & What is the possibility of fully adhering to medication in the future? \\
\hline
\end{tabular}

Notes: aLikert five-point scales from I (totally agree) to 5 (totally disagree) were used to measure parents' affectional attitude. 'Likert seven-point scales from I (no change at all) to 7 (completely relieved) were used to measure functional attitude. Questions were used to measure functional attitude, eg, "To what extent do you expect your child's symptom(s) to be relieved?" 'Likert seven-point scales from I (totally disagree with medication treatment) to 7 (totally agree with medication treatment) were used to measure other important people's opinions to medication use. 'Likert seven-point scales from I (totally follow the suggestion/opinion) to 7 (totally follow the suggestion/ opinion) were used to measure the extent to which parents follow others' suggestions and agree with others' opinions. 'Likert seven-point scales from I (not at all) to 7 (definitely yes) were used to measure direct control of medication use. 'Likert seven-point scales from I (not able to overcome at all) to 7 (definitely able to overcome) were used to measure indirect control of medication use, including five items covering the barriers to medication adherence. sLikert seven-point scales from I (absolutely not possible) to 7 (absolutely adherent to medication use) were used to measure intention, eg, to what extend you will be willing to allow your children to take medication in the future.

Abbreviation: ADHD, attention deficit hyperactivity disorder.

Table S4 Types of medication taken by children in the intervention group and control group

\begin{tabular}{lllll}
\hline Medication name & \multicolumn{2}{l}{ Intervention group (n=44) } & & \multicolumn{2}{c}{ Control group (n=45) } \\
\cline { 2 - 3 } & First follow-up, $\mathbf{n}(\%)$ & Second follow-up, $\mathbf{n}(\%)$ & & First follow-up, $\mathbf{n}(\%)$ \\
\hline Methylphenidate & $8(18.2)$ & $12(27.3)$ & Second follow-up, $\mathbf{n}(\%)$ \\
Atomoxetine & $36(81.8)$ & $32(72.7)$ & $31.1)$ & $9(20.0)$ \\
\hline
\end{tabular}

Note: First follow-up is I month after initiating medication, and second follow-up is 3 months after initiating medication.

\section{Reference}

1. MTA Cooperative Group. National Institute of Mental Health Multimodal Treatment Study of ADHD follow-up: 24-month outcomes of treatment strategies for attention-deficit/hyperactivity disorder. Pediatrics. 2004;113(4):754-761.

\section{Publish your work in this journal}

Neuropsychiatric Disease and Treatment is an international, peerreviewed journal of clinical therapeutics and pharmacology focusing on concise rapid reporting of clinical or pre-clinical studies on a range of neuropsychiatric and neurological disorders. This journal is indexed on PubMed Central, the 'PsycINFO' database and CAS,

\section{Dovepress}

and is the official journal of The International Neuropsychiatric Association (INA). The manuscript management system is completely online and includes a very quick and fair peer-review system, which is all easy to use. Visit http://www.dovepress.com/testimonials.php to read real quotes from published authors. 